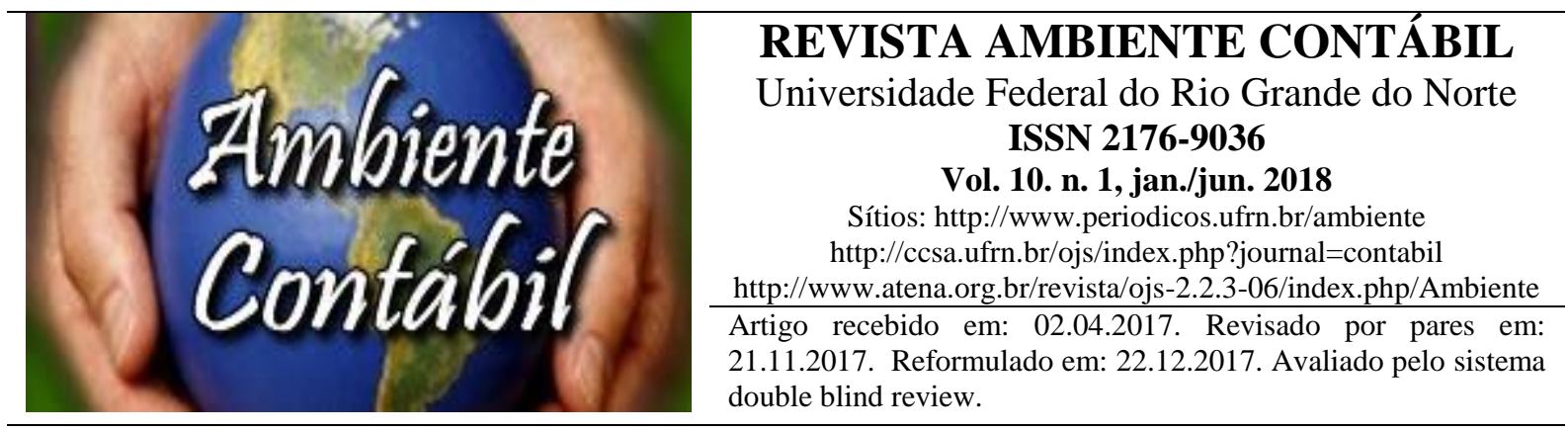

\title{
POLÍTICAS DE DIVIDENDOS EM EMPRESAS DO SETOR ELÉTRICO
}

\section{DIVIDEND POLICIES IN THE BRAZILIAN ELECTRIC POWER INDUSTRY}

\section{POLÍTICAS DE DIVIDENDOS EN EMPRESAS DEL SECTOR ELÉCTRICO}

\section{Autores}

Nayara Alves Rebouças Graduada em Ciências Contábeis pela Universidade Federal do Ceará - UFC Endereço: Av. da Universidade, 2431, Benfica, Fortaleza-CE, CEP: 60.020-180

Telefone: (85) 99219-0385. Identificadores (ID):

Lattes: http://lattes.cnpq.br/7377671651386294 Redalyc: http://www.redalyc.org/autor.oa?id=22269

ORCID: https://orcid.org/0000-0002-6490-2041

E-mail: nayara_reboucas@ hotmail.com

Rafael Sales Almendra

Mestre em Administração e Controladoria pela Universidade Federal do Ceará - UFC.

Professor do Departamento de Administração do Instituto Federal de Educação, Ciência e Tecnologia do Piauí - IFPI - Endereço: Av. Odilon Araújo, 1760, Piçarra, Teresina-PI, CEP: 64.017-280 - Telefone: (86) 99953-3938 Identificadores (ID):

Lattes: http://lattes.cnpq.br/3445859953494127 Research Gate: https://www.researchgate.net/profile/Rafael_Almendra Redalyc: http://www.redalyc.org/autor.oa?id=22214

E-mail: rafael.almendra@ifpi.edu.br

Alessandra Carvalho de Vasconcelos

Doutora em Engenharia de Produção pela Universidade Federal de Santa Catarina - UFSC.

Professora do Departamento de Contabilidade da Universidade Federal do Ceará - UFC. Endereço: Av. da Universidade, 2431, Benfica, Fortaleza-CE, CEP: 60.020-180 - Telefone -

(85) 3366-7802

Identificadores (ID):

Lattes: http://lattes.cnpq.br/3674132552801030

Research Gate: https://www.researchgate.net/profile/Alessandra_Vasconcelos3

ORCID: https://orcid.org/0000-0002-6480-5620

E-mail: alevasconcelos.ufc@gmail.com 
[Trabalho apresentado no $20^{\circ}$ Congresso Brasileiro de Contabilidade, realizado em setembro de 2016, em FortalezaCE]

\title{
RESUMO
}

Com base na Teoria do Pássaro na Mão, foram identificados alguns fatores que se correlacionam com as políticas de dividendos adotadas pelas empresas do setor elétrico listadas na BM\&FBovespa. Analisaram-se os demonstrativos financeiros e formulários de referência de 33 empresas, alusivos a 2014. Também foram extraídos dados do sistema Economática ${ }^{\circledR}$, e a investigação envolveu a análise de correlação de Spearman e a análise de homogeneidade (Homals). Considerou-se como política de dividendos a análise conjunta dos índices Payout Ratio e Dividend Yield. A partir das recomendações da literatura foram levantadas seis hipóteses, as quais relacionam a política de dividendos com as variáveis: segmento de listagem, concentração acionária, fluxo de caixa, tamanho, risco e origem do capital. Constatou-se associação entre empresas com maior fluxo de caixa e participantes do Novo Mercado e Payout e Yield altos, corroborando os preceitos da Teoria do Pássaro na Mão. Entretanto, a análise de correlação indicou apenas à aceitação da hipótese $\mathrm{H}_{3}$, que previa que o fluxo de caixa se correlacionaria com a política de dividendos. Nenhuma evidência pode ser inferida sobre a correlação entre as políticas de dividendos das empresas e os demais fatores investigados. Os resultados trazem implicações para a compreensão das políticas de dividendos e para a governança corporativa no mercado de capitais brasileiro. As evidências observadas para a amostra contribuem para os gestores na identificação dos fatores que se correlacionam com a política de dividendos nas empresas e para os investidores que pretendem decidir em que alocar seu capital.

Palavras-chave: Políticas de dividendos. Teoria do Pássaro na Mão. Setor elétrico.

\begin{abstract}
In light of the Theory of Bird in Hand, we tested the correlation between a set of variables and the dividend policies adopted by electric utilities traded on BM\&FBovespa. Information was retrieved from 2014 financial reports and reference forms issued by 33 firms, and from the Economatica ${ }^{\circledR}$ database. The findings were submitted to Spearman correlation analysis and homogeneity analysis (Homals). Dividend policy was proxied by the combination of payout ratio (PR) and dividend yield (DY). Based on recommendations in the literature, six hypotheses were formulated correlating dividend policy with the variables listing segment, shareholder concentration, cash flow, company size, risk, and source of capital. Firms in the 'New Market' listing segment with large cash flows were associated with high PR and DY, as predicted by the Bird-in-Hand Theory, but only one of the hypotheses $\left(\mathrm{H}_{3}\right.$ : correlation between cash flow and dividend policy) was confirmed in the correlation analysis. No significant correlation was found between dividend policies and the remaining variables. The results have implications for our understanding of dividend policy and corporate governance on the Brazilian capital market. The evidence presented in this study may help managers identify factors associated with dividend policy and investors make informed choices.
\end{abstract}

Keywords: Dividend policy. Bird in Hand Theory. Power industry.

\section{RESUMEN}

Con base en la Teoría del Pájaro en la Mano, fueron identificados algunos factores que se correlacionan con las políticas de dividendos adoptadas por las empresas del sector eléctrico listadas en la BM\&FBovespa. Se analizaron los demostrativos financieros y formularios de referencia de 33 empresas, alusivos a 2014. También fueron extraídos datos del sistema Economática®, y la investigación involucró el análisis de la correlación de Spearman y el Revista Ambiente Contábil - ISSN 2176-9036 - UFRN - Natal-RN. v. 10. n. 1, p. 308 - 328, jan.jjun. 2018. 
análisis de homogeneidad (Homals). Se consideró como política de dividendos el análisis conjunto de los índices Payout Ratio y Dividend Yield. A partir de las recomendaciones de la literatura fueron levantadas seis hipótesis, las cuales relacionan la política de dividendos con las variables: segmento de lista, concentración accionaria, flujo de caja, tamaño, riesgo y el origen del capital. Se constató una asociación entre empresas con mayor flujo de caja y participantes del Nuevo Mercado y Payout e Yield altos, corroborando los preceptos de la Teoría do Pájaro en la Mano. Sin embargo, el análisis de correlación ha indicado apenas a la aceptación de la hipótesis H3, que preveía que el flujo de caja se correlacionaría con la política de dividendos. Ninguna evidencia puede ser inferida sobre la correlación entre las políticas de dividendos de las empresas y los demás factores investigados. Los resultados traen implicaciones para la comprensión de las políticas de dividendos y para la gobernanza corporativa en el mercado de capitales brasileño. Las evidencias observadas para la muestra contribuyen para los gestores en la identificación de los factores que se correlacionan con la política de dividendos en las empresas y para los inversionistas que pretenden decidir em que destinar su capital.

Palabras chave: Políticas de dividendos. Teoría de los Pájaros en la Mano. Sector eléctrico.

\section{INTRODUÇÃO}

Dentre as distintas modalidades de remuneração dos acionistas, destaca-se o pagamento de dividendos, a mais comum no Brasil, e que Assaf Neto e Lima (2010) definem como a parcela do lucro líquido distribuída com os acionistas, geralmente em dinheiro, a título de remuneração do capital investido na empresa.

Fonteles et al. (2012) e Viana Júnior e Ponte (2016) entendem que os dividendos são importantes por possuir um elevado conteúdo informacional. Segundo Brealey, Myers e Allen (2008), essa importância deve-se ao fato de que, ao optar pelas empresas que lhe pareçam mais rentáveis, o investidor leva em conta o pagamento de dividendos como um diferencial. Recusase, portanto, a aceitar aquelas empresas cujas demonstrações financeiras não espelhem a realidade, por duvidar que elas conseguirão obter altos lucros no longo prazo, de modo a garantir um elevado índice de distribuição de dividendos.

No mesmo sentido, Hahn et al. (2010) consideram que ao pagar dividendos, a empresa pode estar sinalizando que vem obtendo boa rentabilidade, valorizando, dessa forma, a sua ação, e aumentando o próprio valor.

Ainda na mesma linha, Novis Neto e Saito (2002) consideram que quanto maior for o Dividend Yield - relação entre o dividendo pago por ação e a cotação da ação na data -, maior será o retorno anormal acumulado da ação no período pós-pagamento de dividendos. Assim, esses autores veem a distribuição de dividendos como uma forma de diminuir a assimetria de informações entre os investidores, aumentando, portanto, o valor da empresa (NOVIS NETO; SAITO, 2002).

Nesse contexto, a decisão da empresa entre reter o lucro líquido e reinvesti-lo ou distribuí-lo com os acionistas pode ser definida como a sua política de dividendos. Para se saber quanto foi distribuído em forma de dividendos e quanto foi retido para reinvestimento, utilizase o Payout, o qual corresponde à razão entre os dividendos distribuídos e o lucro líquido (ASSAF NETO; LIMA, 2010).

Segundo Bodie e Merton (2002), a política de dividendos diz respeito ao pagamento em dinheiro aos acionistas, permanecendo constantes tanto seus investimentos, quanto as decisões relacionadas à contração de empréstimos.

Devido à grande importância dos dividendos, em 2010 a Bolsa de Valores Mercadorias e Futuros (BM\&FBovespa) criou o Índice Dividendos (IDIV), que objetiva oferecer uma visão segmentada do mercado acionário, medindo o desempenho das ações das companhias que se

Revista Ambiente Contábil - ISSN 2176-9036 - UFRN - Natal-RN. v. 10. n. 1, p. 308 - 328, jan./jun. 2018. 
destacaram quanto à remuneração dos investidores, sob a forma de dividendos e juros sobre o capital próprio (BM\&FBOVESPA, 2014).

O presente estudo baseia-se na Teoria do Pássaro na Mão, de Gordon (1963) e Lintner (1962), também conhecida como Teoria da Relevância dos Dividendos, que destaca a preferência dos investidores pela distribuição dos dividendos.

Levando em conta que a política de dividendos pode variar significativamente de empresa para empresa (FORTI; PEIXOTO; ALVES, 2015), o estudo se norteia pela seguinte questão: Quais os principais fatores correlacionados com as políticas de dividendos adotadas pelas empresas do setor elétrico?

Algumas pesquisas evidenciam que diversos fatores institucionais correlacionam-se com as distintas políticas de dividendos (ADJAOUD; BEN-AMAR, 2010; AL SHABIBI; RAMESH, 2011; DALMÁCIO; CORRAR, 2007; FONTELES et al., 2012; HAHN et al., 2010; JIRAPORN; KIM; KIM, 2008; MOTA, 2007; SANTANA, 2005; SROUR, 2005), muitas delas realizadas em economias desenvolvidas, e apresentando resultados divergentes. Diante disso, o presente estudo tem como objetivo geral identificar os principais fatores correlacionados às políticas de dividendos nas empresas do setor elétrico. Tem ainda os seguintes objetivos específicos: (i) caracterizar as empresas da amostra em termos de porte, origem do capital, concentração acionária e segmento de listagem; e (ii) analisar a associação entre as políticas de dividendos nas empresas da amostra e suas características institucionais.

Optou-se pelo setor elétrico por ser aquele com maior número de empresas e maior participação (30,5\%) na carteira teórica do Índice Dividendos (IDIV), da BM\&FBovespa, no dia 22/06/2015 (término da coleta de dados). Além disso, é consenso que "as empresas que compõem o setor elétrico assumem uma função importante para o desenvolvimento da sociedade" (SILVA et al., 2016, p. 94).

Destarte, o estudo se justifica por abordar um dos assuntos mais críticos em Finanças, tanto pela abrangência das áreas envolvidas, como pela histórica falta de consenso sobre a matéria no meio acadêmico, como afirmam Ferreira Júnior et al. (2010) e Viana Júnior e Ponte (2016). A propósito, Leite, Bambino e Hein (2017, p. 206) consideram que "política de dividendos é um assunto em aberto entre os profissionais de finanças, com muitas perguntas não respondidas, algumas perguntas respondidas de maneiras contraditórias, e outras questões pendentes a serem feitas". Ademais, segundo relatam Fonteles et al. (2012), a política de dividendos constitui um dos pontos fundamentais a considerar quando o investidor pretende decidir em que alocar seu capital.

Diante do exposto, o estudo busca expandir a literatura existente, ao apresentar novos resultados empíricos com a intenção de mitigar aqueles contraditórios, e, assim, auxiliar os gestores na identificação dos fatores que se relacionam com a política de dividendos nas firmas. Além disso, o estudo centra-se na análise em firmas do setor elétrico listadas na BM\&FBovespa, onde a demanda crescente por energia torna as empresas desse setor fundamentais para o desenvolvimento econômico e social em todos os países, bem como pelo fato de que as firmas desse setor gerarem resultados financeiros diferenciados, conforme mencionado em Brugni et al. (2012) e Viana Júnior et al. (2017).

\section{REFERENCIAL TEÓRICO}

Este capítulo apresenta os eixos teóricos, com uma revisão de literatura, contemplando a política de dividendos e seus aspectos legais, as teorias sobre política de dividendos, os estudos empíricos anteriores e o desenvolvimento das hipóteses de pesquisa. 


\subsection{POLÍTICA DE DIVIDENDOS E SEUS ASPECTOS LEGAIS}

Na visão de Assaf Neto e Lima (2010), há duas formas mais comuns de remuneração pelo capital investido nas companhias brasileiras: os dividendos e os juros sobre o capital próprio.

No Brasil, os juros sobre o capital próprio foram regulamentados pela lei $\mathrm{n}^{\circ} 9.249$ (BRASIL, 1995), com o intuito de evitar o aumento da carga tributária das empresas após a retirada da correção monetária nas demonstrações financeiras. $\mathrm{O}$ montante dos juros sobre o capital próprio é limitado a 50\% do maior valor entre o lucro líquido antes do imposto de renda e o lucro acumulado de períodos anteriores, mas admite a dedução do lucro real para cálculo do imposto de renda. Além disso, os juros sobre o capital próprio efetivamente pagos são descontados do valor dos dividendos obrigatórios (ASSAF NETO; LIMA, 2010).

Já os dividendos, segundo Ross (2010), são valores pagos aos acionistas, em dinheiro ou ações, representando um retorno direto ou indireto à sociedade, pelo capital fornecido.

Segundo Iudícibus et al. (2013), os dividendos podem ser classificados quanto à ordem (dividendos prioritários e dividendos não prioritários), quanto ao recebimento (dividendos cumulativos e dividendos não cumulativos) e quanto à forma de apropriação dos lucros (dividendos mínimos, dividendos fixos e dividendos obrigatórios).

Em relação à ordem, Iudícibus et al. (2013) ensinam que os acionistas com direito a dividendos prioritários têm preferência na participação dos lucros, de modo que, no caso de o lucro não ser suficiente para distribuição de dividendos a todos os acionistas, aqueles terão prioridade.

Quanto ao recebimento, Iudícibus et al. (2013) e Ross (2010) indicam que os dividendos devidos aos acionistas preferenciais podem ser cumulativos ou não cumulativos. No caso dos cumulativos, quando não houver lucro suficiente para ser distribuído, serão transferidos para futuros exercícios.

Quanto à forma de apropriação, os dividendos fixos e os dividendos mínimos são conceituados segundo a distribuição do lucro excedente. Os dividendos mínimos admitem a participação no lucro remanescente, o que não ocorre em relação aos dividendos fixos. Os dividendos obrigatórios foram criados para proteger os acionistas das companhias negligentes, cujos estatutos sejam omissos na fixação da parcela do lucro a ser distribuída (IUDÍCIBUS et al., 2013). Para os casos em que o estatuto é omisso, a lei $n^{\circ} 6.404$ (BRASIL, 1976) estabelece o pagamento de pelo menos $25 \%$ do lucro líquido.

De acordo com Damodaran (2002), a política de dividendos determina a proporção do capital a se retirar do negócio, repassando-se-a aos acionistas. No mesmo sentido, Poli e Procianoy (1993) afirmam que a política de dividendos é a decisão entre pagar dividendos e reter lucro.

Brigham e Ehrhardt (2010) opinam que para ser considerada ótima, a política de dividendos deve conseguir o equilíbrio entre os dividendos atuais e o crescimento futuro, de forma a maximizar a cotação da ação. A política de dividendos também pode transmitir para os acionistas informações sobre o desempenho da empresa, razão pela qual a decisão pelo pagamento de dividendos é considerada muito importante (ROSS, 2010).

Nesse sentido, cada empresa adota a política de dividendos que mais se adéqua a sua realidade particular. As empresas em desenvolvimento, com acelerado crescimento, geralmente não pagam altos dividendos, enquanto as empresas estáveis, com altos fluxos de caixa e menos projetos, tendem a pagar valores maiores (DAMODARAN, 2002). 


\subsection{TEORIAS SOBRE POLÍTICA DE DIVIDENDOS}

Na busca por um melhor entendimento das políticas de dividendos, foram desenvolvidas algumas importantes teorias, destacando-se: a Teoria da Irrelevância dos Dividendos, proposta por Miller e Modigliani (1961); a Teoria do Pássaro na Mão, defendida por Gordon (1963) e Lintner (1962); a Teoria da Preferência Tributária, atribuída a Damodaran (2002); a Teoria da Agência, idealizada por Jensen e Meckling (1976); e a Teoria da Sinalização, concebida por Ross (1977).

A Teoria da Irrelevância dos Dividendos (MILLER; MODIGLIANI, 1961) defende que, em mercados de capitais perfeitos, os dividendos são irrelevantes para os acionistas, por não serem capazes de alterar a cotação da ação. Segundo Assaf Neto e Lima (2010), essa teoria foi formulada em um mercado sem imperfeições, em que não existe imposto, nem custo de transações nas emissões e negociações, o que geralmente não ocorre no mundo real.

A Teoria do Pássaro na Mão (GORDON, 1963; LINTNER, 1962), chamada de Teoria da Relevância dos Dividendos, ao considerar a firma inserida num mercado de incertezas e a aversão dos investidores ao risco, preconiza que o pagamento de dividendos reduz o risco do investidor, e, consequentemente, diminui o custo de capital, elevando a cotação da ação; ou seja, há uma correlação direta entre a política de dividendos da empresa e o seu valor de mercado. Assim, a Teoria do Pássaro na Mão defende que os investidores preferem receber dividendos ao risco de não obter ganhos de capitais futuros, pois, segundo Ambrozini, Bonacim e Assaf Neto (2008), somente os dividendos são considerados ganhos certos no presente, enquanto a futura valorização da ação é sempre uma incerteza.

Nessas circunstâncias, e de acordo com Assaf Neto e Lima (2010), uma maior distribuição corrente de dividendos reduz a incerteza dos investidores; ou seja, ainda que os dividendos venham a representar uma distribuição de lucros menor quando comparada a um eventual ganho futuro, os acionistas preferem garanti-los, resultando em possíveis variações no nível de risco da empresa.

Conforme preconiza a Teoria do Pássaro na Mão, mais vale um dividendo na mão do que um ganho de capital incerto no futuro, o que leva os investidores a valorizar mais a ação da companhia que distribui seus resultados com os acionistas (LOSS; SARLO NETO, 2006).

Como os gestores utilizam os dividendos para indicar a sustentabilidade do negócio por meio do crescimento dos lucros (FORTI; PEIXOTO; ALVES, 2015; LINTNER, 1962), a política de dividendos considerada ótima seria, segundo a Teoria do Pássaro na Mão, aquela que balanceia dividendos correntes e crescimento futuro, com o propósito de maximizar a cotação da ação (BACHMANN et al., 2012).

A Teoria da Preferência Tributária, por seu turno, afirma que devido ao fato de a tributação sobre os dividendos ser mais onerosa do que sobre os ganhos de capital, a opção por ganhos de capital se torna mais atraente (DAMODARAN, 2002). Devido às desvantagens tributárias do recebimento de dividendos, os acionistas podem preferir que a empresa retenha a maioria de seus lucros, dispondo-se a pagar mais nas empresas com baixa distribuição do que naquelas com alta distribuição (BRIGHAM; EHRHARDT, 2010). No caso do Brasil, os dividendos não são tributados, de acordo com a lei n 9.249 (BRASIL, 1995). Assim, Fonteles et al. (2012) mencionam que há um indicativo de que as companhias podem adotar a política de altos dividendos.

A Teoria da Agência considera que a empresa é um conjunto de "contratos", em que os acionistas têm direito sobre os ativos e fluxos de caixa. Esses direitos geram conflitos entre seus detentores, acionistas e gestores, que procuram agir em defesa dos próprios interesses, num contexto de separação entre propriedade e gestão, de forma que o objetivo principal de cada um consiste em maximizar sua própria utilidade (JENSEN; MECKLING, 1976).

Revista Ambiente Contábil - ISSN 2176-9036 - UFRN - Natal-RN. v. 10. n. 1, p. 308 - 328, jan./jun. 2018. 
Segundo a Teoria da Sinalização, quando divulga alterações na sua política de dividendos, a empresa está enviando informações para o mercado financeiro, já que seus agentes examinam todas as medidas implementadas no meio empresarial, com o intuito de avaliar suas implicações nos fluxos de caixa futuros e no valor da empresa, conforme elucida Ross (1977).

Ainda de acordo com a Teoria da Sinalização, as mudanças na política de dividendos podem influenciar a cotação da ação. Quando a empresa aumenta a distribuição de dividendos, o mercado tende a reagir positivamente, pois a confiança no seu desempenho futuro caminha na mesma direção. Quando ocorre o contrário, a redução é recebida como uma má notícia acerca das expectativas, segundo Loss e Sarlo Neto (2003).

Segundo González (1998), a Teoria da Sinalização ajuda os investidores a compreender melhor o significado das mudanças na política de dividendos no que tange aos sinais positivos ou negativos que elas podem enviar para o mercado. Corroborando esse entendimento, Fonteles et al. (2012) mencionam que a teoria se resume a dois princípios básicos: o dos sinais positivos ou confiáveis que uma alteração na política de dividendos pode sinalizar para o mercado, e o dos sinais negativos ou não confiáveis.

Sobre os dividendos de sinal positivo e confiáveis, Weston e Copeland (1992) assim consideram aqueles que cumprem as seguintes principais condições: a) a gerência deve ser estimulada a enviar sinais verdadeiros, mesmo em caso de noticiar situação desfavorável; b) os sinais de uma empresa de sucesso não podem ser facilmente copiados por concorrentes sem sucesso; c) os sinais devem ser positivamente correlacionados com os eventos observáveis; e d) a gerência deve selecionar o método mais econômico e efetivo para enviar sinais ao mercado.

Já sobre dividendos de sinal negativo ou não confiáveis, González (1998) considera que a sua diminuição pode ser interpretada pelos investidores como um sinal negativo, como se a empresa estivesse enfrentando dificuldade financeira. Essa situação, geralmente, acaba acarretando uma queda na cotação da ação. Damodaran (2002) ensina que se uma empresa que nunca tivesse pago dividendos, mas que tenha registrado alto crescimento e retorno em seus projetos, decidisse passar a distribuí-los, seus acionistas poderiam interpretar a medida como um sinal de que os projetos da firma não são tão lucrativos como antes.

Ainda de acordo com a Teoria da Sinalização, o valor dos dividendos pode ser estratégico, desde o momento em que seja possível incrementá-lo como uma forma de transmitir sinais positivos para o mercado. Assim, a teoria pode ser usada para atrair investidores e captar recursos (FONTELES et al., 2012).

As cinco teorias aqui apresentadas são, individual ou conjuntamente, bastante utilizadas como base teórica de pesquisas sobre a temática.

\subsection{ESTUDOS ANTERIORES E DESENVOLVIMENTO DAS HIPÓTESES}

Considerando a relevância do tema para o mercado e para o meio acadêmico, diversos estudiosos têm procurado identificar os fatores determinantes da política de dividendos. Ao analisar a eficácia das formas alternativas de governança corporativa, Srour (2005) percebeu que as empresas dos segmentos Novo Mercado e ADR Nível II distribuem mais dividendos e obtêm maiores retornos em momentos de crise.

Santana (2005) investigou a relação entre o Dividend Yield e o retorno total ao acionista, considerando os fatores determinantes da política de dividendos em empresas listadas na Bovespa no período de 1998 a 2003. Utilizou como variáveis o setor de atividade, a capacidade de geração de lucro e as oportunidades de crescimento e investimento. Verificou que não há relação estatisticamente positiva entre o Dividend Yield e o retorno total ao acionista, e que não se pode afirmar que as variáveis sejam capazes de afetar positiva ou negativamente essa relação. 
Ao estudar as empresas listadas na Bovespa no período de 2000 a 2005, Mota (2007) avaliou as motivações envolvidas na definição das respectivas políticas de distribuição do lucro, analisando como se dá a escolha de seus instrumentos, entre dividendos, juros sobre o capital próprio e recompra de ações. Identificou que fatores como, por exemplo, a existência de fluxo de caixa, o não comprometimento com o endividamento, a preocupação com a governança corporativa e a existência de poucas oportunidades de investimento levam as empresas a distribuir a maior proporção dos seus lucros na forma de dividendos e/ou de juros sobre o capital próprio.

Adjaoud e Ben-Amar (2010) investigaram a correlação entre a qualidade da governança corporativa e a política de dividendos, nas empresas do Canadá. Adotando como amostra o conjunto de empresas listadas na Bolsa de Toronto no período de 2002 a 2005, verificaram que as companhias com governança corporativa mais forte fizeram pagamento de dividendos mais elevados. Os resultados apontam ainda uma associação positiva entre o tamanho da empresa, o nível dos fluxos de caixa livres e o pagamento de dividendos.

Jiraporn, Kim e Kim (2008) investigaram como a qualidade da governança corporativa afeta a política de dividendos. Usando uma grande amostra de empresas com governança, com dados extraídos do Institutional Shareholder Services (ISS), constataram que aquelas com melhor governança têm mais aptidão para pagar dividendos e até pagar dividendos maiores. Os resultados são fortes para o controle de um grande número de características específicas da empresa, incluindo tamanho, alavancagem, rentabilidade, oportunidades de crescimento, possível efeito fiscal e ciclo de vida.

Al Shabibi e Ramesh (2011) estudaram a associação entre boas práticas de governança corporativa e política de dividendos em empresas do Reino Unido. Definiram características da firma e fatores de governança corporativa como prováveis variáveis explicativas da política de dividendos. Concluíram que fatores como independência do conselho de administração, rentabilidade, tamanho e risco têm impacto sobre as decisões relacionadas a política de dividendos.

Em estudo sobre os possíveis fatores condicionantes de políticas de dividendos elevados nas empresas participantes do Índice Dividendos (IDIV), da BM\&FBovespa, Fonteles et al. (2012) observaram um maior cuidado com a governança corporativa.

Com base na fundamentação exposta, o estudo formula a primeira hipótese:

$\mathrm{H}_{1}$ - O segmento de listagem se correlaciona com a política de dividendos.

Dalmácio e Corrar (2007) investigaram se a concentração acionária nas empresas listadas na Bovespa no período de 1998 a 2005 tem alguma correlação com a política de dividendos. Os resultados do estudo demonstram que um aumento na concentração acionária ocasiona um aumento no valor dos dividendos, mas percebeu-se uma expectativa de que aquele aumento provoque uma significativa redução no percentual de Payout. Assim, conclui-se que, nas empresas brasileiras, a composição pode explicar, em parte, a política de dividendos.

Hahn et al. (2010) analisaram a correlação entre a concentração acionária e o nível de Payout nas companhias listadas na Bovespa no período de 1996 a 2008. Os autores separaram a amostra do estudo em dois grupos: um, reunindo as empresas com todos os valores de Payout, e o outro, reunindo aquelas com os valores de Payout acima de $25 \%$. No segundo grupo constataram uma correlação positiva entre a concentração acionária e o índice de Payout.

Ao se levar em conta que é destinado ao acionista o maior lucro possível, e não o lucro máximo, e caso ele seja o único proprietário, supõe-se que ele procure maximizar a riqueza da empresa. Assim, formula-se a segunda hipótese:

$\mathrm{H}_{2}$ - A concentração acionária se correlaciona com a política de dividendos.

Vancin e Procianoy (2014) estudaram os fatores que influenciam as companhias listadas na BM\&FBovespa a pagar dividendos, através de uma nova abordagem, considerando a questão

Revista Ambiente Contábil - ISSN 2176-9036 - UFRN - Natal-RN. v. 10. n. 1, p. 308 - 328, jan./jun. 2018. 
legal. Para realizar a pesquisa, foi utilizada a regressão múltipla, distribuindo-se a amostra em dois grupos: empresas que pagam dividendos acima do obrigatório e empresas que pagam apenas o obrigatório. Analisaram 1.118 distribuições de dividendos no período de 2007 a 2011. Percebeu-se que o modelo de regressão composto por empresas que distribuem valores acima do obrigatório apresenta maior poder de explicação. Isso pode ser parcialmente justificado pelo fato de essas empresas haverem decidido, elas próprias, pagar dividendos acima do obrigatório, já que as demais estão simplesmente cumprindo a legislação.

Marques et al. (2015) estudaram a correlação entre política de dividendos e o valor de mercado nas companhias listadas na BM\&FBovespa no período de 2009 a 2014. Utilizaram duas proxies como variáveis dependentes de valor de mercado: $Q$ de Tobin e cotação da ação. A política de dividendos foi considerada variável independente, adotando como proxy o índice de Payout, e como variáveis de controle o tamanho e a alavancagem financeira. Apesar de investigar o valor de mercado utilizando duas proxies distintas, o estudo não encontrou nenhuma correlação entre valor de mercado e as políticas de dividendos adotadas pelas firmas.

Viana Júnior e Ponte (2016) investigaram os determinantes da política de dividendos em 105 companhias, sendo 58 brasileiras, listadas na BM\&FBovespa, e 47 dos EUA, listadas na bolsa de valores de Nova Iorque, no período de 2008 a 2014. O estudo considerou como variável dependente o índice Payout, e como variáveis independentes tamanho, lucro líquido, estabilidade dos dividendos, oportunidades de crescimento, fluxo de caixa e endividamento. A análise da regressão realizada apontou que as variáveis lucro líquido e estabilidade dos dividendos podem explicar a política de dividendos nas empresas brasileiras, enquanto as variáveis estabilidade dos dividendos, valor de mercado e fluxo de caixa explicam a política de dividendos nas firmas norte-americanas.

Vancin e Procianoy (2016) procuraram identificar os aspectos relevantes para a distribuição de dividendos no Brasil, constatando, por meio de regressão logística, que Retorno sobre o Patrimônio Líquido (Return On Equity - ROE), liquidez, tamanho, investimento, instabilidade da receita e estabilidade da política de dividendos são alguns fatores estatisticamente significantes para esse objetivo.

Leite, Bambino e Hein (2017) analisaram a correlação entre política de dividendos dividendos totais, dividendos pagos por ação e Dividend Yield - e desempenho econômicofinanceiro em empresas brasileiras e chilenas, identificando que, em linhas gerais, a política de dividendos influencia negativamente o desempenho econômico-financeiro nas organizações dos dois países.

Diante do exposto, depreendem-se a terceira, a quarta e a quinta hipóteses do estudo:

$\mathrm{H}_{3}$ - O fluxo de caixa se correlaciona com a política de dividendos;

$\mathrm{H}_{4}-\mathrm{O}$ tamanho da empresa se correlaciona com a política de dividendos;

$\mathrm{H}_{5}-\mathrm{O}$ risco da firma se correlaciona com a política de dividendos.

Em sua tese de doutorado, Carvalhal da Silva (2002) analisou os efeitos da estrutura de controle e propriedade no valor de mercado, estrutura de capital e política de distribuição de dividendos das empresas brasileiras e constatou que existe uma relação entre estrutura de controle/propriedade e valor de mercado, estrutura de capital e Payout. Adicionalmente, o estudo de Carvalhal da Silva (2002) sinalizou que as análises acerca da estrutura de propriedade das empresas não devem ficar restritas à propriedade direta, mas se aprofundarem nas questões sobre quem é o controlador final das empresas.

Silva (2004) analisou os efeitos da estrutura de controle e propriedade no valor de mercado das ações, estrutura de capital e política de dividendos, buscando avaliar, entre outros aspectos, se existe relação entre concentração de controle e pagamento de dividendos, por meio do índice de Payout. Entre as principais conclusões destaca-se a não identificação de diferença de Payout das empresas em função da origem do capital. 
Os resultados de Santos e Salotti (2007) indicaram, quanto à origem do capital (nacionais, estrangeiras e estatais), que as empresas estatais, em quase a sua totalidade, têm utilizado apenas o limite legal para pagamento de remuneração aos detentores de capitais na forma de juros sobre o capital próprio (JSCP).

Com base na fundamentação exposta, o estudo formula a sexta hipótese:

$H_{6}-$ A origem de capital se correlaciona com a política de dividendos.

Ademais, outros pontos são focos da atenção de estudiosos acerca da política de dividendos e suas implicações.

Nakayama e Salotti (2014) pesquisaram a divulgação de informações sobre operações de combinação de negócios ocorridas no Brasil em 2010, quando passou a viger o Pronunciamento Técnico CPC 15. Utilizaram como variáveis de controle a listagem nos segmentos diferenciados da BM\&FBovespa, o setor de atuação, a origem do capital (estatal, privado nacional ou privado estrangeiro) e o porte relativo da empresa adquirida, em relação à empresa adquirente, sendo analisadas 76 operações de combinação de negócios, realizadas por 40 companhias.

Almeida, Tavares e Pereira (2014) pesquisaram os determinantes financeiros para explicar a política de dividendos nas empresas não financeiras cotadas na Euronext Lisbon, no período de 1997 a 2011, concluindo que para o mercado de capitais português as empresas adotam política de dividendos de acordo com a Teoria da Relevância dos Dividendos. Assim como Fonteles et al. (2012), este estudo elege a Teoria do Pássaro na Mão como norteadora, haja vista que no cenário brasileiro há uma propensão à distribuição de dividendos elevados.

Diante do exposto, e conforme mencionam Leite, Bambino e Hein (2017) e Nagem e Amaral (2013), apesar de a política de dividendos ser abordada pela literatura de Finanças desde a década de 1960, ainda constitui um dos temas de maior discussão e críticas, devido a sua abrangência e à falta de convergência dos resultados, o que justifica a realização deste estudo.

\section{METODOLOGIA}

A população do estudo reúne 64 empresas do setor elétrico listadas na BM\&FBovespa. Desse contingente, foram excluídas 31 companhias que não disponibilizaram informações acerca da variável risco, resultando em uma amostra de 33 empresas.

Os dados referentes aos atributos financeiros e econômicos das empresas foram levantados a partir dos formulários de referência e do sistema Economática ${ }^{\circledR}$, correspondentes ao exercício de 2014.

Neste estudo, a análise das políticas de dividendos das empresas da amostra abrange os índices Payout Ratio e Dividend Yield, como adotado por Ferreira Júnior et al. (2010). O Payout Ratio refere-se à porcentagem de lucro líquido a ser distribuída com os acionistas (ASSAF NETO; LIMA, 2010). Já o Dividend Yield, segundo Novis Neto e Saito (2002), mensura o rendimento referente aos dividendos por ação, em relação à cotação da ação. Ademais, constituem variáveis de estudo aquelas apresentadas no Quadro 1. 


\section{Quadro 1 - Descrição e fundamentação das variáveis selecionadas}

\begin{tabular}{|c|c|c|c|c|}
\hline \multirow{7}{*}{ 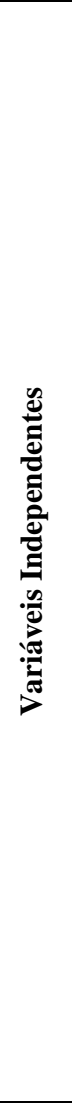 } & Variável & Proxy & Fonte & Referência \\
\hline & $\begin{array}{c}\text { Origem de } \\
\text { Capital (OC) }\end{array}$ & $\begin{array}{l}\text { Capital predominante: } \\
\text { estatal ou privado } \\
\text { (nacional ou estrangeiro) }\end{array}$ & 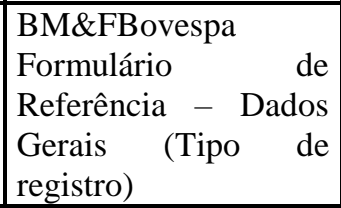 & $\begin{array}{l}\text { Lima, Góis e De Luca (2014) } \\
\text { Nakayama e Salotti (2014) } \\
\text { Rezende e Fontes Filho (2013) } \\
\text { Zucoloto e Cassiolato (2013) }\end{array}$ \\
\hline & $\begin{array}{l}\text { Concentração } \\
\text { Acionária } \\
\text { (CONCAC) }\end{array}$ & $\begin{array}{l}\text { Proporção (\%) } \text { das ações } \\
\text { com direito a voto } \\
\text { pertencentes ao acionista } \\
\text { majoritário }\end{array}$ & $\begin{array}{l}\text { BM\&FBovespa } \\
\text { Formulário de } \\
\text { Referência (Item 15.1) }\end{array}$ & $\begin{array}{l}\text { Dalmácio e Corrar (2007) } \\
\text { Fonteles et al. (2012) } \\
\text { Hahn et al. }(2010) \\
\text { Mota (2007) }\end{array}$ \\
\hline & $\begin{array}{l}\text { Fluxo de Caixa } \\
\text { (FLC) }\end{array}$ & $\begin{array}{l}\text { ROA = Lucro Líquido / } \\
\text { Ativo }\end{array}$ & Economática ${ }^{\circledR}$ & $\begin{array}{l}\text { Adjaoud e Ben-Amar (2010) } \\
\text { Fonteles } \text { et al. } \text { (2012) } \\
\text { Jiraporn, Kim e Kim (2008) } \\
\text { Mota (2007) } \\
\text { Santana (2005) }\end{array}$ \\
\hline & $\begin{array}{l}\text { Tamanho } \\
\text { (TAM) }\end{array}$ & Log do Ativo & Economática ${ }^{\circledR}$ & $\begin{array}{l}\text { Adjaoud e Ben-Amar (2010) } \\
\text { Al Shabibi e Ramesh (2011) } \\
\text { Fonteles et al. (2012) } \\
\text { Mota (2007) }\end{array}$ \\
\hline & $\begin{array}{l}\text { Risco } \\
\text { (RISC) }\end{array}$ & $\begin{array}{l}\text { *BETA BETA = Covar } \\
\text { [OscAção, OscInd] / Dvp } \\
\text { [OscInd] }\end{array}$ & Economática ${ }^{\circledR}$ & $\begin{array}{l}\text { Adjaoud e Ben-Amar (2010) } \\
\text { Al Shabibi e Ramesh (2011) } \\
\text { Assaf Neto (2014) }\end{array}$ \\
\hline & $\begin{array}{l}\text { Segmento de } \\
\text { Listagem } \\
(\mathrm{GOV})\end{array}$ & $\begin{array}{l}\text { Critérios de segmentação } \\
\text { segundo a BM\&FBovespa }\end{array}$ & $\begin{array}{|lr|}\text { BM\&FBovespa } & \\
\text { Formulário re de } \\
\text { Referência } & - \text { Dados } \\
\text { cadastrais } & \text { (Valores } \\
\text { mobiliários) } & \\
\end{array}$ & $\begin{array}{l}\text { Fonteles et al. (2012) } \\
\text { Mota (2007) } \\
\text { Srour (2005) }\end{array}$ \\
\hline \multirow{2}{*}{ 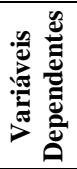 } & $\begin{array}{l}\text { Payout Ratio } \\
\text { (Payout) }\end{array}$ & $\begin{array}{l}\text { Dividendo pago / Lucro } \\
\text { Líquido }\end{array}$ & Economática ${ }^{\circledR}$ & $\begin{array}{l}\text { Dalmácio e Corrar (2007) } \\
\text { Hahn et al. (2010) }\end{array}$ \\
\hline & $\begin{array}{l}\text { Dividend Yield } \\
\quad \text { (Yield })\end{array}$ & $\begin{array}{l}\text { Dividendos anuais } \\
\text { ação / preço da ação }\end{array}$ & Economática ${ }^{\circledR}$ & $\begin{array}{l}\text { Novis Neto e Saito (2002) } \\
\text { Santana (2005) }\end{array}$ \\
\hline
\end{tabular}

*Nota: Covar = função covariância; Dvp = função desvio-padrão.

Fonte: Elaborado pelos autores.

Como apontado por estudos anteriores, as empresas da amostra foram caracterizadas quanto a aspectos como origem de capital, concentração acionária, fluxo de caixa, tamanho, risco e segmento de listagem da BM\&FBovespa. No que tange à origem de capital, foram classificadas em privada (nacional ou estrangeira) ou estatal; e quanto ao segmento de listagem, utilizou-se a classificação dos níveis diferenciados de governança corporativa da BM\&FBovespa (Nível 1, Nível 2 e Novo Mercado).

Com o propósito de atender ao objetivo geral e validar as hipóteses de pesquisa, realizou-se um teste de correlação via coeficiente de Spearman, já que por meio do teste de Kolmogorov-Smirnov os dados não se mostraram normais (FIELD, 2009). Para atender ao segundo objetivo específico, realizou-se uma análise de homogeneidade (Homals), com o intuito de se verificar a associação entre os construtos (FÁVERO et al., 2009).

Considerando-se que a Homals utiliza dados não-métricos, as variáveis sofreram as transformações necessárias, por meio de uma categorização de acordo com os seus quartis, como adotado por Lima (2009) e Lima, Góis e De Luca (2014), conforme exibe a Tabela 1. 
Tabela 1 - Categorização das variáveis

\begin{tabular}{l|c|c|c|c|c}
\hline Nível & ConcAc & FLC & TAM & Payout & Yield \\
\hline Baixo & até 0,5194 & até 0,0039 & até 15,1854 & 0,0000 & até 0,0089 \\
\hline Médio-baixo & 0,5195 a 0,8150 & 0,0040 a 0,0530 & 15,1855 a 15,6457 & 0,0001 a 0,3054 & 0,0090 a 0,0442 \\
\hline Médio-alto & 0,8151 a 0,9448 & 0,0531 a 0,0750 & 15,6458 a 16,4103 & 0,3055 a 0,8074 & 0,0443 a 0,1572 \\
\hline Alto & acima de 0,9448 & acima de 0,0750 & acima de 16,4103 & acima de 0,8074 & acima de 0,1572 \\
\hline
\end{tabular}

Fonte: Elaborada pelos autores.

Os dados foram coletados e analisados a partir do que se estabeleceu nos procedimentos metodológicos e em conformidade com o objetivo proposto neste estudo.

\section{ANÁLISE DOS RESULTADOS}

No presente capítulo são apresentadas a análise de correlação de Spearman, a análise de homogeneidade (Homals) e a discussão dos resultados.

\subsection{CARACTERIZAÇÃO DAS EMPRESAS}

O Gráfico 1 apresenta a caracterização das 33 empresas da amostra quanto à origem de capital.

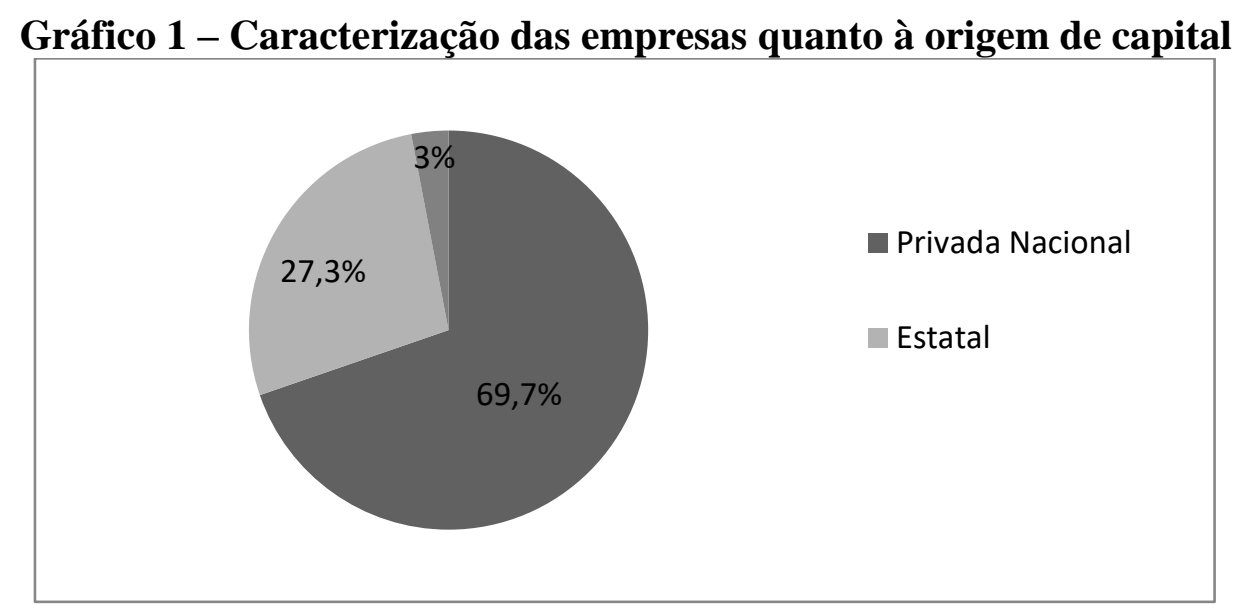

Fonte: Elaborado pelos autores.

No que tange à origem de capital, 23 empresas, ou seja, mais da metade da amostra $(69,7 \%)$, possuem capital do tipo privado nacional, enquanto somente uma (3\%) apresenta capital do tipo privado estrangeiro. Destaca-se ainda que nove $(27,3 \%)$ possuem controle do Estado. Esse perfil assemelha-se apenas parcialmente ao das empresas pesquisadas por Santos e Salotti (2007), que examiram a remuneração aos sócios e acionistas de uma amostra composta por $70 \%$ de empresas nacionais, $24 \%$ de empresas estrangeiras e uma minoria de empresas estatais, com proporções semelhantes ao estudo de Guerreiro e Santos (2006). Nada obstante, a fim de se conhecer a qualidade da governança corporativa, as empresas foram distribuídas quanto ao segmento de listagem da BM\&FBovespa (Gráfico 2). 


\section{Gráfico 2 - Caracterização das empresas quanto ao segmento de listagem}

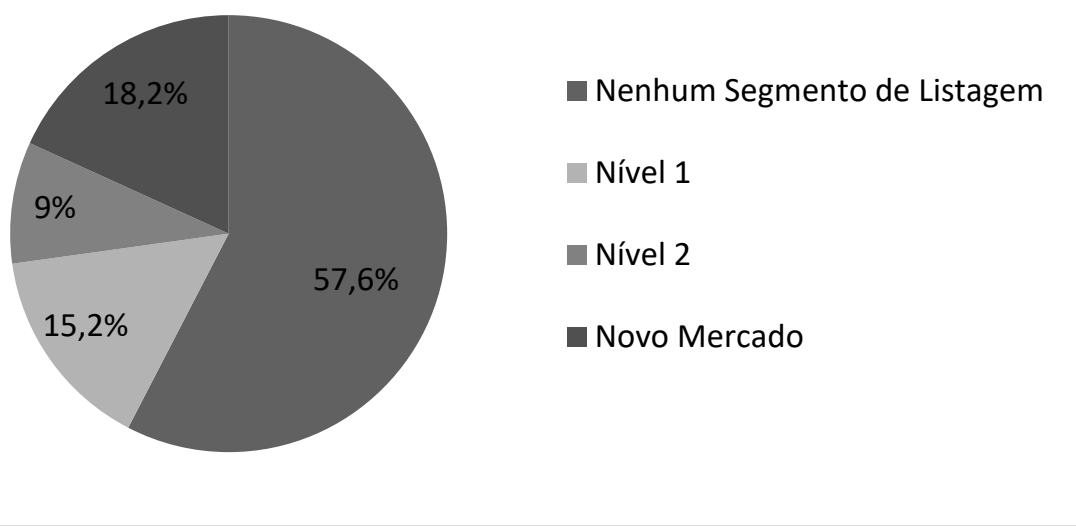

Fonte: Elaborado pelos autores.

Quanto ao segmento de listagem, diferentemente do esperado, mais da metade das empresas $(57,6 \%)$ não participa de nenhum dos níveis diferenciados de governança corporativa da BM\&FBovespa, ou seja, cumpre tão-somente as exigências mínimas da legislação brasileira para as companhias de capital aberto. Dos três segmentos especiais de listagem da bolsa de valores brasileira, o Novo Mercado é o predominante, com 18,2\% da amostra, seguido do Nível $1, \operatorname{com} 15,2 \%$.

\subsection{ASSOCIAÇÃO ENTRE POLÍTICA DE DIVIDENDOS E ALGUNS FATORES EMPRESARIAIS}

Antes de se proceder aos testes estatísticos, fez-se necessária a análise das características das empresas, através da estatística descritiva das variáveis. Ressalta-se que as variáveis origem de capital e segmento de listagem foram excluídas dessa análise, pelo fato de serem consideradas não-métricas ou dummies. A Tabela 2 mostra o resultado da estatística descritiva dos dados.

Tabela 2 - Estatística descritiva das variáveis

\begin{tabular}{|c|c|c|c|c|c|c|c|}
\hline \multicolumn{2}{|l|}{ Variável } & Payout & Yield & ConcAc & Beta & TAM & FLC \\
\hline \multicolumn{2}{|l|}{ N Válido } & 33 & 33 & 33 & 33 & 33 & 33 \\
\hline \multicolumn{2}{|l|}{ Média } & 0,4548 & 0,1101 & 0,7425 & 0,5166 & 15,454 & 0,0121 \\
\hline \multicolumn{2}{|l|}{ Mediana } & 0,3054 & 0,0442 & 0,815 & 0,52 & 15,6457 & 0,053 \\
\hline \multicolumn{2}{|c|}{ Desvio-padrão } & 0,7668 & 0,1539 & 0,2241 & 0,7326 & 1,66748 & 0,1798 \\
\hline \multicolumn{2}{|c|}{ Coeficiente de variação } & $168,6 \%$ & $139,8 \%$ & $30,2 \%$ & $141,8 \%$ & $10,8 \%$ & $1.483,7 \%$ \\
\hline \multicolumn{2}{|c|}{ Variância } & 0,588 & 0,024 & 5,0251 & 0,537 & 2,78 & 0,032 \\
\hline \multicolumn{2}{|l|}{ Mínimo } & $-1,08$ & 0,00 & 0,2645 & $-1,09$ & 10,76 & $-0,92$ \\
\hline \multicolumn{2}{|c|}{ Máximo } & 3,17 & 0,67 & 0,9997 & 2,21 & 18,79 & 0,18 \\
\hline \multicolumn{2}{|c|}{ Amplitude } & 4,25 & 0,67 & 0,7352 & 3,3 & 8,03 & 1,1 \\
\hline \multicolumn{2}{|c|}{ Soma } & 15,01 & 3,63 & 24,5055 & 17,05 & 509,98 & 0,4 \\
\hline \multirow{3}{*}{ Percentis } & 25 & 0 & 0,0089 & 0,5194 & 0 & 15,1854 & 0,0039 \\
\hline & 50 & 0,3054 & 0,0442 & 0,815 & 0,52 & 15,6457 & 0,053 \\
\hline & 75 & 0,8074 & 0,1572 & 0,9448 & 0,9484 & 16,4103 & 0,075 \\
\hline
\end{tabular}

Fonte: Elaborada pelos autores.

Primeiramente, destacam-se as variáveis correspondentes a política de dividendos, Payout e Yield. O Payout possui a maior média $(0,4548)$, a maior amplitude $(4,25)$ e a maior dispersão, com desvio-padrão 0,7668. Enquanto isso, o Yield comportou-se de forma oposta, 
apresentando a menor média $(0,1101)$, a menor amplitude $(0,67)$ e a menor dispersão, com desvio-padrão 0,1539 .

No tocante às demais variáveis, a partir dos dados da Tabela 2, percebe-se que o fluxo de caixa possui a menor média entre as variáveis $(0,0121)$, enquanto o tamanho apresenta a maior média $(15,6457)$, a maior amplitude $(8,03)$ e a maior dispersão, com desvio-padrão 1,66748. A concentração acionária é a variável empresarial que apresenta a menor amplitude na distribuição $(0,7352)$.

Com exceção do tamanho, as variáveis consideradas neste estudo mostram valores heterogêneos, já que possuem coeficiente de variação superior a 30\% (FÁVERO et al., 2009). Para se analisar a associação entre política de dividendos e as características empresariais nas firmas da amostra, procedeu-se a uma Homals. As Figuras 1 e 2 exibem os mapas perceptuais resultantes da aplicação dessa técnica.

Figura 1 - Associação entre política de dividendos (Payout e Yield) e fluxo de caixa (ROA)

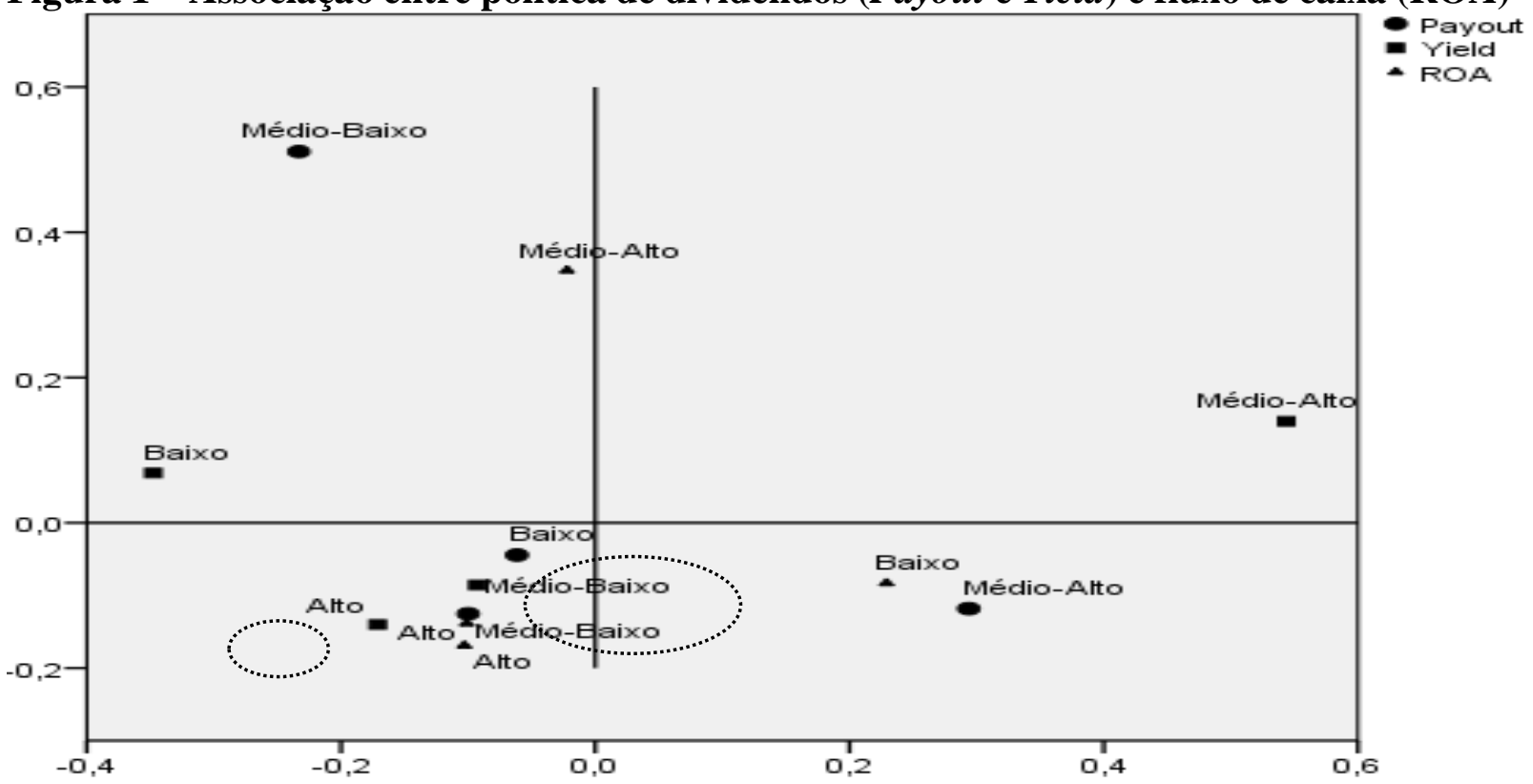

Fonte: Elaborada pelos autores.

De acordo com a Figura 1, as empresas com médio-alto Payout estão associadas a baixo fluxo de caixa (ROA). As firmas com alto Payout e alto Yield associam-se ao fluxo de caixa (ROA) médio-baixo. Diante desses resultados, pode-se afirmar que há uma relação positiva entre política de dividendos e fluxo de caixa.

De forma complementar, a Figura 2 demonstra, por meio de um mapa perceptual, a associação entre política de dividendos e segmento de listagem (qualidade da governança corporativa) nas empresas da amostra. 
Figura 2 - Associação entre política de dividendos (Payout e Yield) e segmento de listagem (GOV)

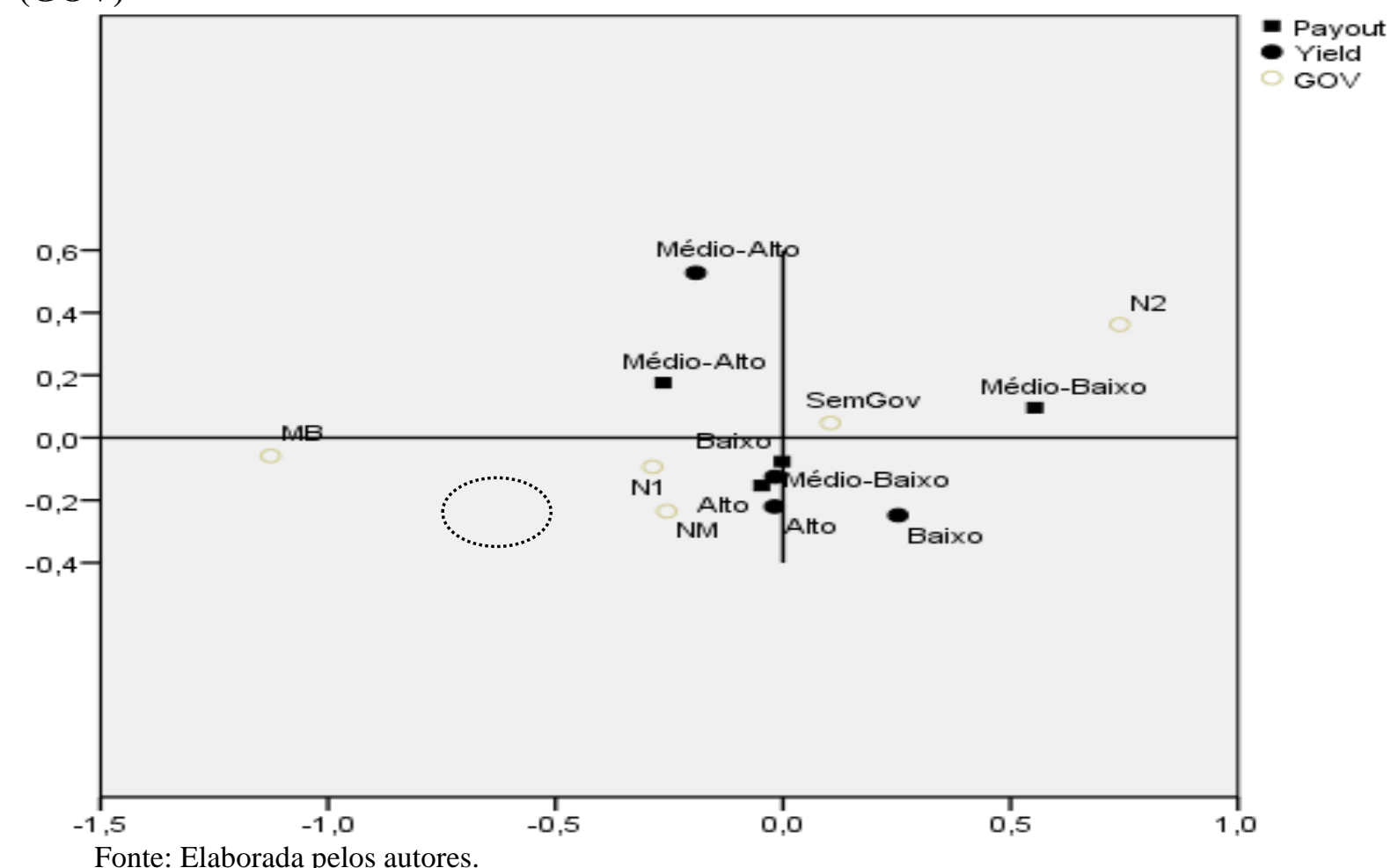

De acordo com a Figura 2, observa-se uma associação entre empresas participantes do Novo Mercado e Payout e Yield altos, indo ao encontro da conclusão de Srour (2005), segundo o qual as empresas do Novo Mercado, ou seja, com melhor governança, distribuem mais lucros sob a forma de dividendos. Diante desse resultado, pode-se dizer que as firmas que adotam melhores práticas de governança corporativa se relacionam com a distribuição de maior parcela do lucro na forma de dividendos e de juros sobre o capital próprio. Resultado semelhante foi encontrado por Fonteles et al. (2012), que identificaram uma correlação entre segmento de listagem da BM\&FBovespa e pagamento de dividendos elevados.

\subsection{CORRELAÇÃO ENTRE POLÍTICA DE DIVIDENDOS E ALGUNS FATORES EMPRESARIAIS}

Para atender ao objetivo geral, realizou-se a análise de correlação de Spearman, cujos resultados são mostrados na Tabela 3 . 
Nayara Alves Rebouças, Rafael Sales Almendra e Alessandra Carvalho de Vasconcelos

Tabela 3 - Análise de correlação de Spearman nas empresas da amostra

\begin{tabular}{|c|c|c|c|c|c|c|c|c|c|c|c|}
\hline Variável & ConcAc & Beta & TAM & ROA & Payout & Yield & D_OC & D_MB & D_N1 & D_N2 & D_NM \\
\hline ConcAc & 1 & & & & & & & & & & \\
\hline Beta &,$- 660\left(^{* *}\right)$ & 1 & & & & & & & & & \\
\hline TAM &,$- 522\left({ }^{* *}\right)$ & ,607( $\left.{ }^{* *}\right)$ & 1 & & & & & & & & \\
\hline ROA & $-0,073$ & $-0,029$ & $-0,093$ & 1 & & & & & & & \\
\hline Payout & $-0,149$ & 0,138 & 0,121 & $628\left(^{* *}\right)$ & 1 & & & & & & \\
\hline Yield & $-0,172$ & 0,137 & 0,062 & $670\left(^{* *}\right)$ & ,847( $\left.{ }^{* *}\right)$ & 1 & & & & & \\
\hline D_OC & $-0,043$ & 0,057 & $-0,029$ & ,357( $\left(^{*}\right)$ & 0,28 & 0,28 & 1 & & & & \\
\hline D_MB & $-0,093$ & $-0,056$ & $-0,074$ & 0,13 & $-0,037$ & $-0,13$ & 0,108 & 1 & & & \\
\hline D_N1 & $-0,089$ &, $426\left(^{*}\right)$ & ,497( $\left.{ }^{* * *}\right)$ & $-0,053$ & 0,062 & 0,053 &,$- 500\left({ }^{* *}\right)$ & $-0,075$ & 1 & & \\
\hline D_N2 & $-0,255$ & 0,066 & 0,1 & 0,155 & $-0,078$ & 0,044 & $-0,043$ & $-0,056$ & $-0,134$ & 1 & \\
\hline D_NM &,$- 578\left(^{* *}\right)$ & ,429(*) & ,396(*) & $-0,041$ & 0,124 & 0,012 & 0,289 & $-0,083$ & $-0,199$ & $-0,149$ & 1 \\
\hline
\end{tabular}

Nota: (*) A correlação é significativa no nível 0,05 (2 extremidades); (**) A correlação é significativa no nível 0,01 ( 2 extremidades).

Fonte: Elaborada pelos autores.

Da Tabela 3, depreende-se que tanto o Payout quanto o Yield, ambos representando a política de dividendos na pesquisa, estão positivamente correlacionados entre si, e, individualmente, correlacionam-se com o fluxo de caixa (ROA), corroborando os achados de Adjaoud e Ben-Amar (2010), Fonteles et al. (2012), Jiraporn, Kim, Kim (2008), Mota (2007) e Santana (2005).

Os resultados apontam que as empresas com maior fluxo de caixa distribuem maior parcela do lucro na forma de dividendos, semelhantemente ao apresentado por Mota (2007) e Viana Júnior e Ponte (2016). Na mesma linha, os achados de Fonteles et al. (2012) sugerem que o fluxo de caixa contribui para uma política de dividendos elevados. Cabe destacar que, com base na análise realizada, as variáveis concentração acionária, risco, tamanho, origem de capital e segmento de listagem não apresentam correlação com a política de dividendos.

Outras inferências podem ser feitas com base nas informações evidenciadas na Tabela 3. A concentração acionária (ConcAc) está negativamente correlacionada com o risco (Beta), o tamanho e o segmento de listagem Novo Mercado. O Beta se correlaciona positivamente com o tamanho e com os segmentos de listagem Novo Mercado e Nível 1. O tamanho (TAM) também se correlaciona com os citados segmentos. Por fim, o fluxo de caixa (ROA) se correlaciona positivamente com a origem de capital, que, por sua vez, correlaciona-se negativamente com o segmento de listagem Nível 1.

Dessa forma, em linhas gerais, os resultados evidenciados estão alinhados com os pressupostos da Teoria do Pássaro na Mão, haja vista que as empresas com alto fluxo de caixa distribuem dividendos elevados. Diante do exposto, e considerando-se os resultados alcançados, a hipótese $H_{3}$ é a única aceita, ou seja, aquela segundo a qual o fluxo de caixa se correlaciona com a política de dividendos.

\section{CONSIDERAÇÕES FINAIS}

O presente estudo objetivou identificar os principais fatores correlacionados às políticas de dividendos nas empresas do setor elétrico listadas na BM\&FBovespa. Para tanto, foram utilizadas como proxies para política de dividendos o Payout Ratio e o Dividend Yield.

A análise descritiva dos dados indicou que a maioria das empresas não participa dos níveis diferenciados de governança corporativa da BM\&FBovespa e que também predominam na amostra empresas com capital do tipo privado nacional.

Com o propósito de analisar a associação entre política de dividendos e características da empresa, realizou-se a análise de homogeneidade (Homals), a qual sugeriu que as empresas

Revista Ambiente Contábil - ISSN 2176-9036 - UFRN - Natal-RN. v. 10. n. 1, p. 308 - 328, jan./jun. 2018. 
com Payout médio-alto estão associadas a um baixo fluxo de caixa, enquanto as firmas com alto Payout e alto Yield associam-se ao fluxo de caixa médio-baixo. Assim, constata-se uma relação positiva entre política de dividendos e fluxo de caixa. Também foi possível observar que as empresas participantes do Novo Mercado estão associadas a Payout e Yield altos, indicando que as empresas de alto padrão de governança corporativa estão relacionadas com a maior distribuição de lucros sob a forma de dividendos.

Os resultados da análise de correlação de Spearman indicam uma correlação positiva entre fluxo de caixa e política de dividendos, sugerindo que as empresas com alto fluxo de caixa se correlacionam com uma maior distribuição de lucros na forma de dividendos. Logo, pode-se conjecturar que ao aumentar a remuneração dos seus acionistas, a firma reduz custos de agência e as incertezas quanto à recebimentos no futuro.

Os achados, portanto, alinham-se com os preceitos da Teoria do Pássaro na Mão, haja vista que as empresas com alto fluxo de caixa distribuem mais dividendos, fato esse que contribui para ampliar a discussão acadêmica sobre a temática e pode auxiliar gestores na identificação dos fatores que se relacionam com a política de dividendos nas firmas, pois de acordo com Brugni et al. (2012) e Viana Júnior et al. (2017), empresas pertencentes ao setor elétrico geram resultados financeiros diferenciados desde o momento da geração de lucro em fases pré-operacionais, havendo uma distribuição antecipada de dividendos, o que torna o setor mais atraente aos investidores.

Algumas limitações deste estudo devem ser consideradas. Uma delas diz respeito à averiguação de apenas um exercício (2014), além da amostra limitada a apenas 33 empresas e restrita a um único setor econômico. Diante disso, sugere-se a realização de novas pesquisas, ampliando-se o tamanho da amostra, bem como o espaço temporal, por meio de um estudo longitudinal. Recomenda-se, ainda, utilizar testes estatísticos mais robustos e considerar outras variáveis empresariais. Também é cabível desenvolver esse estudo utilizando-se outros setores econômicos e fazendo comparações entre eles.

\section{REFERÊNCIAS}

ADJAOUD, F.; BEN-AMAR, W. Corporate governance and dividend policy: shareholders' protection or expropriation? Journal of Business Finance \& Accounting, v. 37, n. 5-6, p. 648$667,2010$.

AL SHABIBI, B. K.; RAMESH, G. An empirical study on the determinants of dividend policy in the UK international research. Journal of Finance and Economics, v. 80, p. 106-120, 2011.

AlMEIDA, L. A. G.; TAVARES, F. O.; PEREIRA, E. T. Determinantes da política de dividendos em Portugal. Revista Universo Contábil, v. 10, n. 4, p. 162-181, 2014.

AMBROZINI, M. A.; BONACIM, C. A. G.; ASSAF NETO, A. O impacto do fim da correção monetária no resultado das companhias brasileiras de capital aberto e na distribuição de dividendos: estudo empírico no período pós-Plano Real. Qualitas Revista Eletrônica, v. 7, n. 2, p. 1-17, 2008.

ASSAF NETO, A. Finanças corporativas e valor. 7. ed. São Paulo: Atlas, 2014.

ASSAF NETO, A.; LIMA, F. G. Fundamentos de administração financeira. São Paulo: Atlas, 2010.

BACHMANN, R. K. B.; KUDLAWICZ, C.; ALMEIDA, V. E.; CHEROBIM, A. P. M.

S. Remuneração aos acionistas: como o mercado precifica a distribuição de dividendos e juros 
sobre capital próprio por empresas do segmento bancário listadas na BM\&FBovespa em 2010. Facef Pesquisa - Desenvolvimento e Gestão, v. 15, n. 2, p. 163-174, 2012.

BM\&FBOVESPA. Bolsa de Valores, Mercadorias e Futuros. Índice de dividendos - IDIV. 2014.

em: <http://www.bmfbovespa.com.br/indices/ResumoIndice.aspx?Indice=IDIV\&Idioma=pt-BR>. Acesso em: 10 nov. 2014.

BODIE, Z.; MERTON, R. C. Finanças. Porto Alegre: Bookman, 2002.

BRASIL. Lei Complementar $n^{\circ} 101$, de 4 de maio de 2000. Estabelece normas de finanças públicas voltadas para a responsabilidade na gestão fiscal e dá outras providências. Diário Oficial [da] República Federativa do Brasil, Brasília, 05 de maio de 2000.

. Lei $\mathrm{n}^{\circ}$ 6.404, de 15 de dezembro de 1976. Dispõe sobre as sociedades por ações. Diário Oficial [da] República Federativa do Brasil, Brasília, 17 de dezembro de 1976.

Lei $\mathrm{n}^{\circ}$ 9.249, de 26 de dezembro de 1995. Altera a legislação do imposto de renda das pessoas jurídicas, bem como da contribuição social sobre o lucro líquido, e dá outras providências. Diário Oficial [da] República Federativa do Brasil, Brasília, 27 de dezembro de 1995.

BREALEY, R. A.; MYERS, S. C.; ALLEN, F. Princípios de finanças corporativas. 8. ed. São Paulo: McGraw-Hill, 2008.

BRIGHAM, E. F.; EHRHARDT, M. C. Administração financeira: teoria e prática. São Paulo: Cengage Learning, 2010.

BRUGNI, T. V.; RODRIGUES, A.; CRUZ, C. F.; SZUTSER, N. IFRIC 12, ICPC 01 e contabilidade regulatória: influências na formação de tarifas do setor de energia elétrica. Sociedade, Contabilidade e Gestão, v. 7, n. 2, p. 104-119, 2012.

CARVALHAL DA SILVA, A. L. A influência da estrutura de controle e propriedade no valor, estrutura de capital e política de dividendos das empresas brasileiras. 128 f. 2002. Tese (Doutorado em Administração) - Universidade Federal do Rio de Janeiro - UFRJ, Instituto COPPEAD de Administração, Rio de Janeiro, 2002.

DALMÁCIO, F. Z.; CORRAR, L. J. A concentração do controle acionário e a política de dividendos das empresas listadas na Bovespa: uma abordagem exploratória à luz da teoria de agência. Revista de Contabilidade e Organizações, v. 1, n. 1, p. 10-23, 2007.

DAMODARAN, A. Finanças corporativas aplicadas: manual do usuário. Porto Alegre: Bookman, 2002.

FÁVERO, L. P. L.; BELFIORE, P.; SILVA, F. L.; CHAN, B. L. Análise de dados: modelagem multivariada para tomada de decisões. São Paulo: Campus, 2009. 
FERREIRA JÚNIOR, W. O. NAKAMURA, W. T.; MARTIN, D. M. L., BASTOS, D. D. Evidências empíricas dos fatores determinantes das políticas de dividendos das firmas listadas na Bovespa. Facef Pesquisa - Desenvolvimento e Gestão, v. 13, n. 2, p. 190-203, 2010.

FIELD, A. Descobrindo a estatística usando o SPSS. 2. ed. Porto Alegre: Artmed, 2009.

FONTELES, I. V.; PEIXOTO JÚNIOR, C. A. P.; VASCONCELOS, A. C.; DE LUCA, M. M. M. Política de dividendos das empresas participantes do índice de dividendos da BM\&FBovespa. Revista Contabilidade Vista \& Revista, v. 23, n. 3, p. 173-204, 2012.

FORTI, C. A. B.; PEIXOTO, F. M.; ALVES, D. L. Fatores determinantes do pagamento de dividendos no Brasil. Revista Contabilidade \& Finanças, v. 26, n. 68, p. 167-180, 2015.

GONZÁLEZ, P. G. As mudanças nas políticas de dividendos e o mercado financeiro. Caderno de Estudos da Fipecafi, v. 10, n. 19, p. 70-81, 1998.

GORDON, M. J. Optimal investment and financing policy. Journal of Finance, v. 28, n. 2, p. 264-272, 1963.

GUERREIRO, R.; SANTOS, A. As empresas que operam no Brasil estão pagando juros sobre o capital próprio? In: CONGRESSO USP DE CONTROLADORIA E CONTABILIDADE, 6 ., 2006, São Paulo. Anais... São Paulo: FEA-USP, 2006.

HAHN, A. V.; NOSSA, S. N.; TEIXEIRA, A. J.; NOSSA, V. Um estudo sobre a relação entre a concentração acionária e o nível de payout das empresas brasileiras negociadas na Bovespa. Revista Contabilidade Vista \& Revista, v. 21, n. 3, p. 15-48, 2010.

IUDÍCIBUS, S.; MARTINS, E.; GELBCKE, E. R.; SANTOS, A. Manual de contabilidade societária: aplicável a todas as sociedades de acordo com as normas internacionais e do CPC. 2. ed. São Paulo: Atlas, 2013.

JENSEN, C.; MECKLING, W. Theory of the firm: managerial behavior, agency costs and ownership structure. Journal of Financial Economics, v. 3, n. 4, p. 305-360, 1976.

JIRAPORN, P.; KIM, J.; KIM, Y. Dividend policy and corporate governance quality. Working Paper. Pennsylvania State University, 2008.

LEITE, M.; BAMBINO, A. C.; HEIN, N. Relação entre política de dividendos e desempenho econômico-financeiro em empresas brasileiras e chilenas. Revista de Gestão, Finanças e Contabilidade, v. 7, n. 1, p. 205-221, jan./abr. 2017.

LIMA, G. A. S. F. Nível de evidenciação x custo da dívida das empresas brasileiras. Revista Contabilidade \& Finanças, v. 20, n. 49, p. 95-108, 2009.

LIMA, P. A. M.; GÓIS, A. D.; DE LUCA, M. M. M. Identidade do acionista majoritário e a distribuição do valor adicionado: uma análise nas empresas listadas na BM\&FBovespa. In: SEMINÁRIOS EM ADMINISTRAÇÃO - SEMEAD, 17., 2014, São Paulo. Anais... São Paulo: FEA-USP, 2014. 
Nayara Alves Rebouças, Rafael Sales Almendra e Alessandra Carvalho de Vasconcelos

LINTNER, J. Dividends, earnings, leverage, stock prices and the supply of capital to corporations. The Review Economics and Statistics, v. 44, n. 3, p. 243-269, 1962.

LOSS, L.; SARLO NETO, A. Política de dividendos, na prática, é importante? Revista Contabilidade \& Finanças, v. 14, n. 1, p. 39-53, 2003.

LOSS, L.; SARLO NETO, A. O inter-relacionamento entre políticas de dividendos e de investimentos: estudo aplicado às companhias brasileiras negociadas na Bovespa. Revista Contabilidade \& Finanças, v. 17, n. 40, p. 52-66, 2006.

MARQUES, D. B.; VIANA JUNIOR, D. B. C.; DOMINGOS, S. R. M.; PONTE, V. M. R. Política de dividendos e valor de mercado: um estudo nas empresas listadas na BM\&FBovespa. In: CONGRESSO NACIONAL DE ADMINISTRAÇÃO E CONTABILIDADE, 2015, 6. Rio de Janeiro. Anais... Rio de Janeiro: FACC/UFRJ, 2015.

MILLER, M. H.; MODIGLIANI, F. Dividend policy, growth, and the valuation of shares. The Journal of Business, v. 34, n. 4, p. 411-433, 1961.

MOTA, D. C. Dividendos, juros sobre capital próprio e recompra de ações: um estudo empírico sobre a política de distribuição no Brasil. 2007. 71 f. Dissertação (Mestrado em Administração de Empresas) - Fundação Getúlio Vargas, São Paulo, 2007.

NAGEM, L. M.; AMARAL, H. F. Retornos anormais das ações pós-pagamento de dividendos: um estudo empírico no mercado brasileiro a partir de 2009. Revista de Contabilidade e Controladoria, v. 5, n. 2, p. 61-73, maio/ago. 2013.

NAKAYAMA, W. K.; SALOTTI, B. M. Fatores determinantes do nível de divulgação de informações sobre combinações de negócios com a entrada em vigor do pronunciamento técnico CPC 15. Revista de Contabilidade \& Finanças, v. 25, n. 66, p. 267-280, 2014.

NOVIS NETO, J. A.; SAITO, R. Pagamentos de dividendos e persistência de retornos anormais das ações: evidências do mercado brasileiro. Revista de Administração da USP, v. 38, n. 2, p. 135-143, 2002.

POLI, B. T. C.; PROCIANOY, J. L. A política de dividendos como geradora de economia físcal e do desenvolvimento do mercado de capitais: uma proposta criativa. Revista de Administração de Empresas, v. 33, n. 4, p. 6-15, 1993.

REZENDE, J. F. C.; FONTES FILHO, J. R. Indutores de alinhamento estratégico: comparações preliminares sobre valor entre empresas de capital privado e empresas estatais no Brasil. Revista de Administração Pública, v. 47, n. 3, p. 695-720, 2013.

ROSS, S. A. The determination of financial structure: the incentive-signalling approach. Bell Journal of Economics, n. 8, p. 23-40, 1977.

ROSS, S. A. Administração financeira. 2. ed. São Paulo: Atlas, 2010.

SANTANA, L. Relação entre dividend yield e retorno das ações abordando aspectos determinantes da política de dividendos: um estudo empírico em empresas com ações negociadas na Bovespa. 2005. 82 f. Dissertação (Mestrado em Ciências Contábeis) - Fundação Instituto Capixaba de Pesquisas em Contabilidade, Economia e Finanças, Vitória, 2005. 
SANTOS, A.; SALOTTI, B. M. Juros sobre o capital próprio - Pesquisa empírica para avaliação do nível de conhecimento das empresas sobre sua utilização. Revista UnB Contábil, v. 10, n. 2, p. 97-118, 2007.

SILVA, A. L. C. Governança corporativa, valor, alavancagem e política de dividendos das empresas brasileiras. Revista de Administração da USP - RAUSP, v. 39, v. 4, p. 348-361, 2004.

SILVA, G. R.; LOPES, J. E. G.; PEDERNEIRAS, M. M. M.; TAVARES, M. F. N.; SILVA, E. E. D. Um estudo sobre o Modelo Fleuriet aplicado na gestão financeira de empresas do setor elétrico listadas na BM\&FBovespa. Revista Ambiente Contábil, v. 8. n. 2, p. 92-109, jul./dez. 2016.

SROUR, G. Práticas diferenciadas de governança corporativa: um estudo sobre a conduta e a performance das firmas brasileiras. Revista Brasileira de Economia, v. 59, n. 4, p. 635-674, 2005.

VANCIN, D. F.; PROCIANOY, J. L. Os fatores determinantes do pagamento de dividendos: um approach inovador. In: ENCONTRO DA ASSOCIAÇÃO NACIONAL DE PÓSGRADUAÇÃO E PESQUISA EM ADMINISTRAÇÃO, 38., 2014. Rio de Janeiro. Anais... Rio de Janeiro: Anpad, 2014.

VANCIN, D. F.; PROCIANOY, J. L. Índices contábeis e a decisão do pagamento de dividendos. Revista Contemporânea de Contabilidade, v. 13, n. 28, p. 57-80, jan./abr. 2016.

VIANA JÚNIOR, D. B. C.; PONTE, V. M. R. Políticas de dividendos: um estudo comparativo entre empresas brasileiras e norte-americanas. Revista Universo Contábil, v. 12, n. 1, p. 25 44, jan./mar. 2016.

WESTON, J. F.; COPELAND, T. E. Managerial finance. 9nd ed. Fort Worth: Dryden Press, 1992.

ZUCOLOTO, G. F.; CASSIOLATO, J. E. Desenvolvimento tecnológico por origem de capital: a experiência brasileira recente. Revista Brasileira de Inovação, v. 12, n. 1, p. 133-170, 2013. 